\title{
KESANTUNAN BERBAHASA ANTARA PEMBELI DAN PENJUAL DI PASAR TRADISIONAL KOTA TERNATE
}

\author{
Anwar Ismail \\ anvidza_tt@yahoo.com \\ Program Studi Pendidikan Bahasa Inggris, FKIP-Universitas Khairun
}

\begin{abstract}
Abstrak
Tujuan penelitian ini adalah untuk mengidentifikasi jenis-jenis tuturan (utterences) yang tidak santun yang dituturkan oleh pembeli dan penjual di pasar tradisional Kota Ternate, menggunakan pendekatan skala kesantunan untuk menentukan jenis-jenis tuturan yang santun. Metode yang digunakan dalam penelitan ini adalah metode kualitatif deskriptif. Penelitian ini menggunakan tiga teknik pengumpulan data, yaitu; 1) teknik observasi (observation); 2) teknik simak dan catat; serta 3) teknik rekam (record). Hasil penelitian menunjukkan bahwa; enam (6) maksim kesantunan yang disampaikan oleh Leech. Semua maksim dilanggar oleh penjual dan pembeli dalam proses jual beli di pasar tradisional. Jumlah tuturan yang dilanggar dalam maksim-maksim itu sebanyak dua puluh lima (25); yang dilanggar penjual adalah dua belas (12) tuturan dan pembeli tiga belas (13) tuturan. Maksim yang paling banyak dilanggar oleh penjual dan pembeli adalah pada maksim maksim kebijaksanaan (tact maxim) yakni enam (6) pelanggaran tuturan. Pada maksim kesimpatian (symphaty maxim) tidak ada pelanggaran tuturan yang dilakukan oleh penjual dan pembeli. Skala kesantunan dijadikan ukuran kesantunan berbahasa dalam sebuah pertuturan disesuaikan dengan konteks pertuturan itu sendiri.
\end{abstract}

Kata kunci: kesantunan, berbahasa, penjual, pembeli

\section{PENDAHULUAN}

Bahasa adalah suatu sistem simbol lisan yang arbitrer yang dipakai oleh anggota suatu masyarakat bahasa untuk berkomunikasi dan berinteraksi antar sesamanya, berlandaskan pada budaya yang mereka miliki bersama (Soenjono Dardjowidjojo, 2005:16). Manusia sebagai anggota suatu masyarakat dalam kehidupannya memerlukan komunikasi untuk dapat menjalin hubungan dengan manusia lain dalam lingkungannya. Ada dua cara untuk dapat melakukan komunikasi, yaitu secara tertulis dan secara lisan. Penggunaan bahasa secara tertulis merupakan hubungan tidak langsung, sedangkan penggunaan bahasa secara lisan adalah hubungan langsung.

Tujuan berkomunikasi adalah untuk menyampaikan pesan dan menjalin hubungan sosial. Dalam penyampaian pesan tersebut biasanya digunakan bahasa verbal baik lisan atau tulis, atau non verbal yang dipahami kedua belah pihak, pembicara dan lawan bicara. Sedangkan tujuan komunikasi untuk menjalin hubungan sosial dilakukan dengan menggunakan beberapa strategi (Yonsa, 2020). Misalnya, dengan menggunakan ungkapan kesopanan, ungkapan implisit dan basabasi. Strategi tersebut dilakukan oleh pembicara dan lawan bicara agar proses komunikasi berjalan baik dalam arti pesan tersampaikan dengan tanpa merusak hubungan sosial diantara keduanya. Dengan demikian, setelah proses komunikasi selesai antara pembicara dan lawan bicara mempunyai kesan yang mendalam, misalnya: kesan simpatik, sopan, ramah, dan santun (Naryanti, 2009).

Ketika berkomunikasi, bahasa menunjukkan pribadi seseorang (Sari, 2017). Karakter, watak, atau pribadi seseorang dapat diidentifikasi dari perkataan yang ia ucapkan. Penggunaan bahasa yang lemah lembut, sopan, santun, sistematis, teratur, jelas dan lugas mencerminkan pribadi penuturnya berbudi (Astuti, 2015). Sebaliknya, melalui penggunaan bahasa yang sarkasme, menghujat, memaki, memfitnah, mengejek atau melecehkan akan mencitrakan pribadi yang tidak berbudi. Masyarakat sebagai pengguna bahasa dalam menjalankan segala aktifitasnya sangat diharapkan untuk bertutur kata dengan menggunakan bahasa yang santun, sehingga dapat menghasilkan sebuah komunikasi yang harmonis antara penutur dan pendengar (Chaer, 2010; Rahardi, 2005). 
Di dalam upaya menciptakan lingkungan masyarakat yang bertutur kata dengan menggunakan bahasa yang santun merupakan hal yang sangat penting karena masyarakat sekarang sedang mengalami kemajuan berpikir dan modern. Setiap perubahan masyarakat menciptakan berbagai konsekuensi yang berkaitan dengan nilai moral dan budaya (Setiawan, 2018). Misalnya, perkembangan Ilmu Pengetahuan dan Teknologi (IPTEK) mempengaruhi pola pikir (mindset) serta berkembangnya media komunikasi sosial. Hal ini dapat mengakibatkan pergeseran nilai budaya dan moral. Maka dengan demikian, nilai komunikasi dengan menggunakan bahasa yang santun di masyarakat di berbagai situasi, kondisi dan tempat. Menurut Rahardi, (2005), kesantunan berbahasa bisa terjadi atau didengarkan di mana saja, bisa terjadi di lingkungan keluarga di rumah, masayarakat, dan di tempat umum. Pasar tradisional merupakan sebuah tempat di mana terdapat berbagai macam aktifitas jual beli antara penjual dan pembeli. Di dalam situasi seperti ini terjadi berbagai macam tuturan yang mengandung nilai kesantunan dan tidak santun terjadi.

Berdasarkan uraian di atas, maka peneliti merasa termotivasi untuk melakukan penelitian tentang kesantunan berbahasa antara penjual dan pembeli dalam proses jual beli di salah satu tempat umum, yaitu Pasar Tradisional Kota Ternate.

a. Maksim kebijaksanaan atau kearifan menggariskan bahwa setiap peserta pertuturan harus meminimalkan kerugian orang lain, atau mernaksimalkan keuntungan bagi orang lain.

b. Maksim penerimaan menghendaki setiap peserta pertuturan untuk memaksimalkan kerugian bagi diri sendiri dan meminimalkan keuntungan diri sendiri.

c. Maksim kemurahan menuntut setiap peserta pertuturan untuk memaksimalkan rasa hormat kepada orang lain dan meminimalkan rasa tidak hormat kepada orang lain.

d. Maksim kerendahan hati menuntut setiap peserta pertuturan untuk memaksimalkan ketidakhormatan pada diri sendiri, dan meminimalkan rasa hormat pada diri sendiri.

e. Maksim kecocokan menghendaki agar setiap penutur dan lawan tutur memaksimalkan kesetujuan di antara mereka; dan meminimalkan ketidaksetujuan di antara mereka.

f. Maksim kesimpatian mengharuskan semua peserta pertuturan untuk memaksimalkan rasa simpati, dan meminimalkan rasa antipati kepada lawan tuturnya. Bila lawan tutur memperoleh keberuntungan atau kebahagiaan penutur wajib memberikan ucapan selamat. Jika lawan tutur mendapat kesulitan atau musibah, penutur sudah sepantasnya menyampaikan rasa duka atau bela sungkawa sebagai tanda kesimpatian.

\section{Skala Kesantunan}

Skala kesantunan adalah peringkat kesantunan, mulai dari yang tidak santun sampai dengan yang paling santun. Berikut akan dibicarakan skala kesantunan dari Lakoff. Menurut Lakoff, (1973) menyatakan ada tiga ketentuan untuk terpenuhi kasantunannya di dalam bertutur. Ketiga ketentuan itu adalah (a) skala formalitas (formality scale); (b) skala ketidaktegasan (hesitancy scale); dan (c) skala kesekawanan (equality scale). Berikut penjelasan secara singkat.

a. Skala formalitas (formality scale) menyatakan bahwa agar peserta pertuturan (penutur dan lawan tutur) merasa nyaman dalam kegiatan bertutur, maka tuturan yang digunakan tidak boleh bernada memaksa dan tidak boleh terkesan angkuh. Di dalam pertuturan, masing-masing peserta pertuturan harus saling menjaga keformalitasan dan menjaga jarak yang sewajarnya dan sealamiah mungkin antara yang satu dengan yang lain.

b. Skala ketidaktegasan disebut juga skala pilihan (optionality scale) menunjukkan agar penutur dan lawan tutur dapat saling merasa nyaman dalam bertutur, maka pilihan-pilihan dalam bertutur harus diberikan oleh kedua belah pihak. Kita tidak boleh bersikap terlalu tegang atau terlalu kaku dalam kegiatan bertutur karena akan dianggap tidak santun. 
c. Skala kesekawanan menunjukkan bahwa agar dapat bersifat santun, kita harus selalu bersikap ramah dan harus selalu mempertahankan persahabatan antara penutur dan lawan tutur. Penutur harus selalu menganggap bahwa lawan tutur adalah sahabat, begitu juga sebaliknya. Rasa persahabatan ini merupakan salah satu prasyarat untuk tercapainya kesantunan.

\section{METODE PENELITIAN}

Metode yang digunakan dalam penelitan ini adalah metode kualitatif deskriptif. Penelitian deskriptif tidak diperlukan administrasi dan pengontrolan terhadap perlakuan. Tidak dimaksudkan untuk menguji hipotesis tertentu, tetapi hanya menggambarkan 'apa adanya' tentang suatu variabel, gejala atau keadaan (Arikunto, 2010; Sugiyono, 2013). Lokasi penelitian ini akan dilakukan di Pasar Tradisional Kota Ternate. Jenis data penelitian terdiri atas tiga, yaitu (1) data catatan lapangan dan (2) data rekam (record) dan dokumentasi. Penelitian ini menggunakan tiga teknik pengumpulan data, yaitu; 1) teknik observasi (observation); 2) teknik simak dan catat, serta 3) teknik rekam (record). Teknik analisa data yang digunakan dalam penelitian ini adalah Model Miles dan Huberman. Menurut Miles dan Huberman dalam Mahsun, (2005); Riduwan, (2004) mengatakan bahwa aktifitas dalam analisis data kualitatif dilakukan secara interaktif dan berlangsung secara terus menerus sampai tuntas, sehingga datanya sudah jenuh. Aktifitas dalam analisis data, yaitu; data reduction (reduksi data), data display (penyajian data) dan conclusion drawing/verification (menyimpulkan/verifikasi data.

\section{HASIL DAN PEMBAHASAN}

\section{A. Hasil Penelitian}

Berdasarkan hasil observasi dan rekaman kepada para sumber data telah ditemukan jenisjenis pelanggaran maksim kesantunan berbahasa. Di bawah ini, peneliti menampilkan data jenis tuturan-tuturan yang tidak santun dan itu merupakan pelanggaran maksim-maksim tuturan yang dilakukan oleh penjual dan pembeli dalam proses jual beli di pasar tradisional Kota Ternate. Data diurutkan dari penjual dan kemudian pembeli.

Tabel 1. Jenis Tuturan Tidak Santun yang Dituturkan oleh Penjual

\begin{tabular}{ll|l}
\hline No & \multicolumn{1}{c}{ Bahasa Melayu Ternate } & \multicolumn{1}{c}{ Bahasa Indonesia } \\
\hline 1 & ci/om mau cari barang apa? & bapak/Ibu mau beli barang apa? \\
\hline 2 & jang cuma lewat. & jangan hanya lewat. \\
\hline 3 & jang ditawar lagi. & jangan ditawar lagi. \\
\hline 4 & cari di tampa lain saja? & cari ditempat lain saja. \\
\hline 5 & barang-barang lagi susah ci/om. & barang-barang lagi mahal bapak/ibu. \\
\hline 6 & BBM nae jadi barang-barang me nae samua. & BBM naik jadi harga barang juga ikut naik. \\
\hline 7 & memang dia pe harga so bagitu. & harganya memang sudah begitu. \\
\hline 8 & beli suda !! tampa lain mahal. & beli saja!! Tempat lain mahal. \\
\hline
\end{tabular}

Tabel 2. Jenis Tuturan Tidak Santun yang Dituturkan oleh Pembeli

\begin{tabular}{cl|l}
\hline No & \multicolumn{1}{c|}{ Bahasa Melayu Ternate } & \multicolumn{1}{c}{ Bahasa Indonesia } \\
\hline 1 & barang so tatinggal. & barang sudah rusak/layu. \\
\hline 2 & sayur so layu-layu. & sayur sudah layu. \\
\hline 3 & rica so busu & cabai sudah busuk. \\
\hline 4 & ikan so tatinggal & ikan sudah busuk. \\
\hline 5 & ikan es jadi tara beli. & ikan es jadi tidak beli. \\
\hline 6 & pe mahal!! & mahal sekali. \\
\hline 7 & pe sadiki skali! & sedikit sekali! \\
\hline 8 & boleh kurang? & boleh ditawar? \\
\hline
\end{tabular}


9 bolom jadi beli

10 saya cari tempat lain dulu. belum dibeli.

saya cari di tempat lain.

\section{B. Pembahasan}

Berdasarkan data pada tabel 1 dan 2 pada hasil penelitian di atas, peneliti mengelompokkan jenis pelanggaran maksim disesuaikan dengan kategori maksim-maksim kesantunan berbahasa, kemudian menampilkan data jenis tuturan yang santun berdasarkan prinsip kesantunan berbahasa menurut Leech, (1982). Data ditampilkan dalam bentuk tabel-tabel berikut.

1. Maksim kebijaksanaan atau kearifan (tact maxim); buatlah kerugian orang lain sekecil mungkin. Buatlah keuntungan orang lain sebesar mungkin.

Tabel 3. Jenis Pelanggaran Maksim Kebijaksanaan atau Kearifan

\section{Tuturan yang tidak Santun \\ Tuturan yang Santun}

\section{PENJUAL}

(1) bapak/Ibu mau cari barang apa?

- Bapak/ibu mau beli apa?

(2) jang hanya lewat?

- Maaf, ada yang bisa dibantu.

(3) cari ditempat lain saja.

- Boleh singgah dulu?

- Mari bapak/ibu lihat-lihat dulu barangnya.

- Bapak/ibu boleh cari di ditempat lain.

- Boleh cari di tempat lain saja.

\section{PEMBELI}

(4) barang sudah rusak/layu. Maaf bapak/ibu, saya cari di tempat lain dulu ya.

(5) sayur sudah layu.

(6) ikan sudah busuk.

2. Maksim penerimaan/kedermawanan (generosity maxim); buatlah keuntungan diri sendiri sekecil mungkin. Buatlah kerugian diri sendiri sebesar mungkin.

Tabel 4. Jenis Pelanggaran Maksim Penerimaan atau Kedermawanan

\section{Tuturan yang tidak Santun}

\section{PENJUAL}

(7) jang ditawar lagi.

(8) barang-barang lagi mahal bapak/ibu.

\section{Tuturan yang Santun}

- Maaf ibu/bapak harganya memang sudah begitu.

- Maaf, tidak bisa kurang lagi ibu/bapak.

- Maaf ibu/bapak harga barang lagi naik.

\section{PEMBELI}

(9) barang sudah rusak/layu.

- Maaf bapak/ibu saya cari di tempat lain dulu ya.

(10) cabai sudah layu.

(11) ikan sudah busuk. 
3. Maksim kemurahan/pujian (approbation maxim); kecamlah orang lain sedikit mungkin. Pujilah orang lain sebanyak mungkin.

Tabel 5. Jenis Pelanggaran Maksim Kemurahan atau Pujian

\begin{tabular}{ll}
\hline \multicolumn{1}{c}{ Tuturan yang tidak Santun } & Tuturan yang Santun \\
\hline PENJUAL & \\
\hline (12) BBM naik jadi harga barang juga ikut naik. & - Maaf ibu/bapak, barang-barang lagi naik harga \\
(13) Cari di tempat lain saja. & ni. \\
& - Bapak/ibu boleh cari di ditempat lain. \\
& - Boleh cari di tempat lain saja \\
\hline PEMBELI & \\
\hline (14) Mahal sekali! & - Maaf, ini terlalu mahal. Apa boleh kurang? \\
(15) Sedikit sekali! & - Terima kasih. \\
(16) Belum dibeli. & - Maaf ibu/bapak, saya cari di tempat lain dulu ya.
\end{tabular}

4. Maksim kesederhanaan/kerendahan hati (modesty maxim); pujilah diri sendiri sedikit mungkin. Kecamlah diri sendiri sebanyak mungkin.

Tabel 6. Jenis Pelanggaran Maksim Kesederhanaan atau Kerendahan Hati

\section{Tuturan yang tidak Santun Tuturan yang Santun}

\section{PENJUAL}

(17) Harga barang-barang lagi naik bapak/ibu

(18) BBM naik jadi harga barang juga ikut naik.

Maaf ibu/bapak, barang-barang lagi naik harga ni.

\section{PEMBELI}

(19) Mahal sekali!

- Maaf, ini terlalu mahal. Apa boleh kurang?

(20) Belum jadi beli.

- Maaf, saya cari di tempat lain dulu ya.

5. Maksim kesepakatan/kesetujuan (agreement maxim); usahakan agar ketidaksepakatan antara diri dan orang lain terjadi sedikit mungkin. Usahakan agar kesepakatan antara diri sendiri dengan orang lain terjadi sebanyak mungkin.

Tabel 7. Jenis Pelanggaran Maksim Kesepakatan atau Kesetujuan

\begin{tabular}{cl}
\hline Tuturan yang tidak Santun & Tuturan yang Santun \\
\hline PENJUAL & \\
\hline (21) jang ditawar lagi. & - Maaf ibu/bapak harganya memang sudah \\
(22) cari di tempat lain saja. & begitu \\
(23) Harganya memang sudah begitu. & - Bapak/ibu boleh cari di ditempat lain. \\
& - Maaf, memang begitu harganya. \\
\hline PEMBELI & \\
\hline (24) mahal sekali! & - Maaf ibu/bapak, boleh ditawar? \\
(25) belum dibeli. & - Maaf ibu/bapak, saya cari di tempat lain dulu \\
& ya.
\end{tabular}


Tabel 8. Rekapitulasi Jenis Pelanggaran Tuturan dalam Setiap Maksim

\begin{tabular}{|c|c|c|c|}
\hline \multirow[t]{2}{*}{ Jenis Maksim } & \multicolumn{2}{|c|}{$\begin{array}{c}\text { Jumlah Tuturan yang } \\
\text { Dilanggar }\end{array}$} & \multirow[t]{2}{*}{ Sub Total } \\
\hline & Penjual & Pembeli & \\
\hline Maksim kebijaksanaan/kearifan (tact maxim) & 3 & 3 & 6 \\
\hline $\begin{array}{l}\text { Maksim penerimaan/kedermawanan (generosity } \\
\text { maxim) }\end{array}$ & 2 & 3 & 5 \\
\hline Maksim pujian/kemurahan (approbation maxim) & 2 & 3 & 5 \\
\hline $\begin{array}{l}\text { Maksim kerendahan hati/kesederhanaan } \\
\text { (modesty maxim) }\end{array}$ & 2 & 2 & 4 \\
\hline $\begin{array}{l}\text { Maksim Kesetujuan/permufakatan (agreement } \\
\text { maxim) }\end{array}$ & 3 & 2 & 5 \\
\hline Maksim kesimpatian (symphaty maxim) & 0 & 0 & 0 \\
\hline Total & 12 & 13 & 25 \\
\hline
\end{tabular}

\section{SIMPULAN}

Dari data yang telah dianalisis di atas, dapat disimpulkan sebagai berikut:

1. Keenam maksim-maksim kesantunan yang disampaikan oleh Leech, semua maksim dilanggar oleh penjual dan pembeli dalam proses jual beli di pasar tradisional. Jumlah tuturan yang dilanggar dalam maksim-maksim itu sebanyak dua puluh lima (25); yang dilanggar penjual adalah dua belas (12) tuturan dan pembeli tiga belas (13) tuturan.

2. Rincian maksim yang dilanggar adalah sebagai berikut; maksim kebijaksanaan (tact maxim) jumlah yang dilanggar oleh penjual tiga (3) dan pembeli tiga (3) tuturan, maksim kemurahan/kedermawanan (generosity maxim) jumlah yang dilanggar oleh penjual dua (2) tuturan dan pembeli tiga (3) tuturan, maksim pujian/kemurahan (approbation maxim) jumlah yang dilanggar oleh penjual dua (2) tuturan dan pembeli tiga (3) tuturan, maksim kerendahan/kesederhanaan (modesty maxim) jumlah yang dilanggar oleh penjual dua (2) tuturan dan pembeli dua (2) tuturan, maksim kesetujuan/permufakatan (agreement maxim) jumlah yang dilanggar oleh penjual tiga (3) tuturan dan pembeli dua (2) tuturan, dan maksim kesimpatian (symphaty maxim) jumlah yang dilanggar oleh penjual dan pembeli tidak (0). Maksim yang paling banyak dilanggar oleh penjual dan pembeli adalah pada maksim maksim kebijaksanaan (tact maxim) yakni enam (6) pelanggaran tuturan. Pada maksim kesimpatian (symphaty maxim) tidak ada pelanggaran tuturan yang dilakukan oleh penjual dan pembeli.

\section{DAFTAR PUSTAKA}

Arikunto. (2010). Prosedur Penelitian Suatu Pendekatan Praktik. In Rineka Cipta. Rineka Cipta. https://doi.org/10.1016/j.minpro.2005.02.005

Astuti, T. (2015). Peranan Pembelajaran Bahasa Dalam Pembentukan Karakter Siswa. Prosiding Seminar Nasional Bulan Bahasa UNIB, 331-340.

Chaer, A. (2010). Kesantunan Berbahasa. Rineka Cipta.

Lakoff, R. (1973). Language and Woman's Place. Language in Society, 2(1), 45-79.

Leech, G. (1982). Prinsip-prinsip Pragmatik (Terjemahan). In Jakarta: Universitas Indonesia.

Mahsun, M. S. (2005). Metode Penelitian Bahasa: tahapan strategi, metode dan tekniknya. PT RajaGrafindo Persada.

Naryanti, A. (2009). Realisasi Kesantunan Berbahasa di kalangan Mahasiswa dalam Berinteraksi dengan Dosen dan Karyawan. Universitas Muhammadiyah Surakarta.

Rahardi, R. K. (2005). Pragmatik: Kesantunan Imperatif Bahasa Indonesia. Erlangga.

Riduwan, M. (2004). Teknik Menyusun Thesis. In Bandung, Alfabeta.

Sari, A. A. (2017). Komunikasi Antarpribadi. Deepublish. 
Setiawan, D. (2018). Dampak Perkembangan Teknologi Informasi dan Komunikasi terhadap Budaya. JURNAL SIMBOLIKA: Research and Learning in Communication Study, 4(1), 6272.

Sugiyono, S. (2013). Metode Penelitian Kualitatif. Alfabeta.

Yonsa, Y. F. Y. (2020). Menjalin Hubungan Ssosial Melalui Kesantunan Berbahasa. Sarasvati, $2(1), 72-77$. 